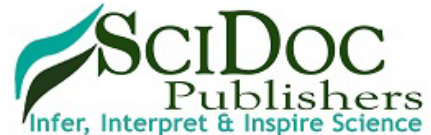

International Journal of Surgery and Research (IJSR) ISSN: 2379-156X

\title{
Assessment of Total Blood Loss in the Management of Periprosthetic Hip Fractures
}

Research Article

Francony F, Pailhé R, Gaillot J, Saragaglia D*

Department of Osteoarthritis and Sport Surgery, Traumatic Emergencies of the Limbs, University Hospital Grenoble-Alpes, South Hospital, Avenue de Kimberley, BP, Echirolles Cedex, France.

\section{Abstract}

Introduction: With the ageing population and the increase in total hip arthroplasties, the incidence of periprosthetic hip fractures (PPHF) is constantly on the rise. Treatment of this fracture often leads to blood loss and anaemia. The aim of this study was to evaluate total blood loss induced by PPHF, to analyse the influence the type of fracture has over blood loss, the influence of treatment on the bleeding and, finally, the blood transfusion rate.

Methods: A prospective study was performed within our department, over a 6-year period from January 1, 2010, to December 31, 2015, including 88 patients. All fractures were treated surgically in accordance with Vancouver guidelines. We evaluated the blood loss volume with formulas based on haemoglobin and haematocrit. Subgroup, stratified according Vancouver Classification, were comparable.

Results: The mean estimated Red Blood Cell loss was $582.19 \mathrm{ml}$. The mean Blood Volume Loss was $1149.31 \mathrm{ml}$ or 1199.35 $\mathrm{ml}$, depending on the formula used. The greatest blood loss was found in Vancouver B3 fractures, followed by Vancouver B2, C and B1 fractures. The volume of blood loss was statistically different between each type of fracture $(\mathrm{P}<0.05)$. The postoperative transfusion rate was $87.5 \%$ with a mean of 3.18 Units of blood concentrates. The blood loss and transfusion rates were different between each type of fracture $(\mathrm{P}<0.05)$.

Discussion: Anaemia is a pejorative factor for mortality and morbidity in PPHF population in previous studies. Recently, many studies have tried to evaluate different pre-operative blood management programs to reduce postoperative anaemia. Conclusion: Periprosthetic hip fractures and their treatments are associated with significant blood loss requiring transfusion of several units of blood.

Keywords: Periprosthetic Hip Fracture; Vancouver Classification; Blood Loss; Transfusion; Orthogeriatrics.

\section{Introduction}

With the ageing population and the increase in total hip arthroplasties (THA), the incidence of periprosthetic hip fractures (PPHF) is constantly on the rise $[1,2]$. Periprosthetic fractures of the femur are the third most frequent complication following THA $[3,4]$. A review of the literature shows that treatment of such fractures induces blood loss and anaemia [5, 6]. Moreover, they are associated with functional impairments and major disabilities and result in high rates of morbidity and mortality $[2,7]$. Both anaemia and blood loss are common risk factors for mortality and morbidity. Elderly patients are particularly vulnerable to blood loss and anaemia, since they have limited physiological reserves and a high prevalence of comorbidities $[8,9]$.
To our knowledge, assessment of the total blood loss and transfusion rate in the treatment of PPHF has not previously been investigated. The aim of this study was to evaluate total blood loss, to analyse the influence of the type of fracture and its treatment on the bleeding and to analyse the blood transfusion rate.

\section{Material and Methods}

\section{Patients}

A prospective study was performed within our department, over a 6-year period from January 1, 2010, to December 31, 2015. All patients presenting PPHF with a surgical indication during this

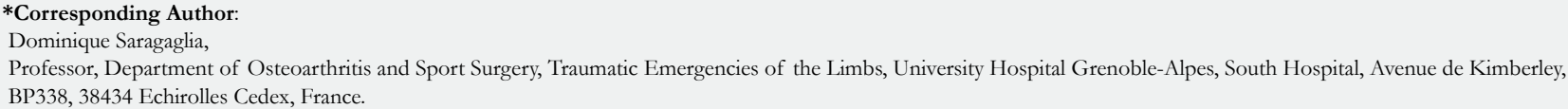

Copyright: Saragaglia $\mathbf{D}^{\circ}$ 2020. This is an open-access article distributed under the terms of the Creative Commons Attribution License, which permits unrestricted use, distribution and reproduction in any medium, provided the original author and source are credited. 
period were included. We were able to analyse data from $88 \mathrm{pa}-$ tients. Data characterising patients by Gender, Age, ASA score [10], ISS score [11], Body Mass Index (BMI), haemoglobin and haematocrit, were collected in medical records. The mean age of the cohort was 82.5 years (SD 9.14), predominantly female, $\mathrm{n}=66$ $(75 \%)$, with a BMI of $25.26 \mathrm{~kg} / \mathrm{m}^{2}$ (SD 5.16 ) and low energy trau$\mathrm{ma}$ (ISS $=9.22)$. At the time of surgery, ASA score was 3 in 43 patients (49\%), 2 in $42(48 \%)$ and 1 in $3(3 \%)$, with pre-operative haemoglobin of $123.55 \mathrm{~g} / 1$ (SD 11.26).

Fracture types were classified by the primary author after analysis of AP and lateral X-rays, in accordance with the Vancouver classification [12] (Figure 1). The majority were found to have Vancouver B1 $(n=30,34.6 \%), B 2(n=23,26.1 \%)$ and C $(n=18,20.5 \%)$ fractures. Moreover, there were 10 (11.4\%) Vancouver B3 and 7 (8\%) Vancouver A fractures. These different groups of patients were comparable for epidemiological data collected, as well as age, gender, BMI, ASA score and ISS score.

All fractures were treated surgically, in accordance with the Vancouver Guidelines [13], with either open reduction and internal fixation (ORIF) for the Vancouver A (Cerclage) (Figure 2), B1 and $\mathrm{C}$ (Plate osteosynthesis) (Figure 3) patterns, a revision prosthesis and ORIF, for the Vancouver B2 pattern (Figure 4) and revision prosthesis for the $\mathrm{B} 3$ pattern (Figure 5) according to the techniques of the centre. Surgeries were performed by senior or assistant surgeons with a special interest in lower limb procedures. We used different surgical approaches for each type of surgery. A

Figure 1. Vancouver classification.
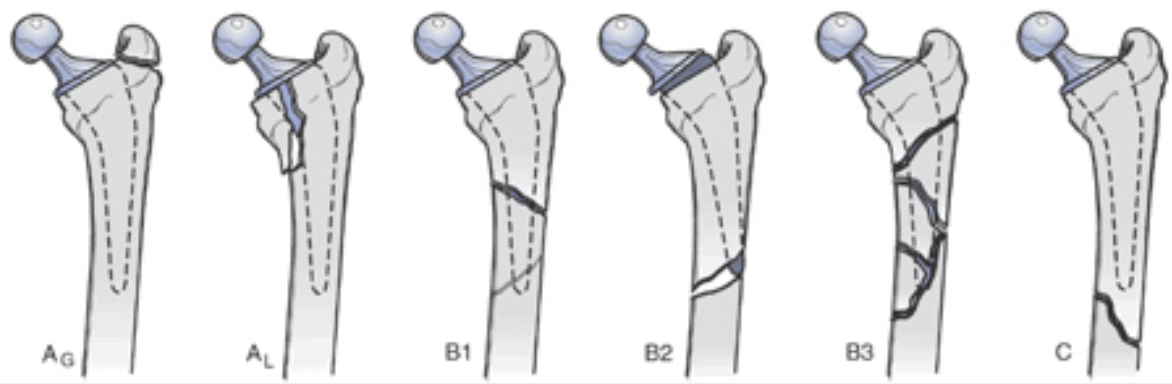

Vancouver A: Located in the trochanteric region ( $\mathrm{L}=$ lesser trochanter, $\mathrm{G}=$ greater trochanter).

Vancouver B: Located around the stem (1= stem well fixed, $2=$ stem loose but good bone stock, $3=$ poor surrounding bone stock). Vancouver C: Located distal to the tip of the stem.

Figure 2. Vancouver AL fracture. Postoperative X-ray after cerclage treatment.

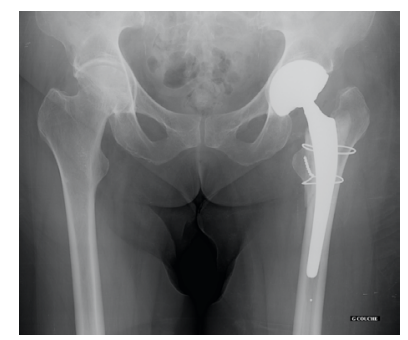

Figure 3. Vancouver B1 fracture. Postoperative X-ray after plate osteosynthesis.

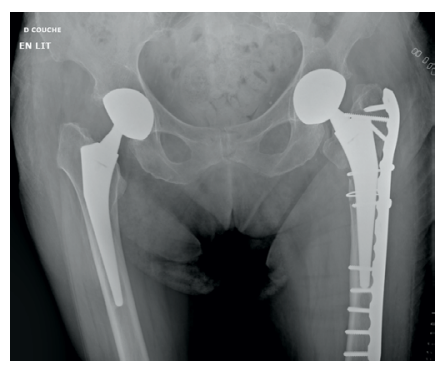

Figure 4. Vancouver B2 fracture. Postoperative X-ray after revision of the hip prothesis and osteosynthesis with a plate.

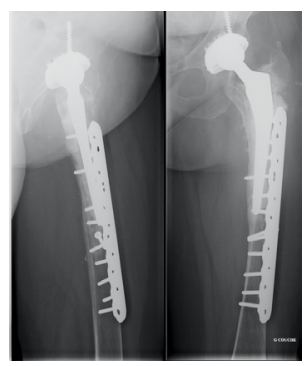


Figure 5. Vancouver B3 fracture. Postoperative X-ray after revision of the prosthesis and cerclages.

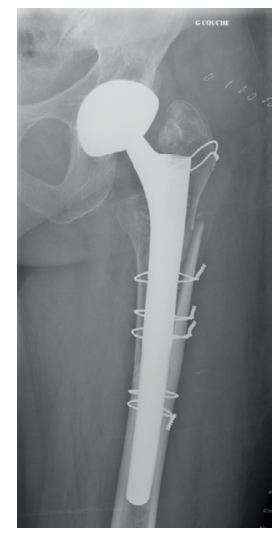

postero-lateral approach was used for Vancouver A and B fractures, and for Vancouver $\mathrm{C}$ fractures we used a lateral approach (sub-vastus). We didn't use tranexamic acid (systemic bolus and/ or local application) in any of our cases. Surgical treatment was delayed in most cases.

\section{Anticoagulation}

All patients received chemical deep venous thrombosis prophylaxis (enoxaparin or heparin - depending on renal function). To improve blood management, patients were prepared according to their anticoagulation. We respected the French national sanitary authority (HAS) recommendations for pre-operative management of anticoagulants. For patient without anticoagulation, preventive thromboprophylaxis therapy was prescribed until the day before surgery. For those with Vitamin K antagonist therapy, a switch to curative heparin therapy was prescribed, and the surgery was performed when the INR reached $<1.5$. For patients with new oral anticoagulant therapy, we respected the duration of suspension necessary for the normalization of coagulation parameters in accordance with the recommendations of the HAS.

\section{Assessment of blood loss}

Haemoglobin and haematocrit levels were measured on admission and on the post-operation day, using a blood test. No patients were transfused intraoperatively or benefited from the Cell Saver blood recapture technique. To be able to perform this study, a literature review was carried out to identify the different formulas proposed. Of these, the authors agreed to select those that seem to be used most frequently. We used three different ways to estimate blood loss (EBL) based on haematocrit and haemoglobin.

The blood volume (BV) was estimated using Nadler's formula [14]. To evaluate the haematocrit, we used 2 methods: Mercuriali's formula [15] and Ward's formula [16]. To evaluate the haemoglobin, we used Meunier's formula [17].

\section{Transfusion data}

The guideline transfusion protocol for patients was in accordance with recommendations of HAS. The following transfusion thresholds of haemoglobin during the perioperative period are recommended: less than $7 \mathrm{~g} / \mathrm{dl}$ for people with no specific antecedents, less than $8-9 \mathrm{~g} / \mathrm{dl}$ in people with a history of cardiovascular disease and less than $10 \mathrm{~g} / \mathrm{dl}$ in people who do not clinically tolerate lower haemoglobin concentrations, or who have acute coronary insufficiency, or proven heart failure. Information concerning transfusion was collected in blood transfusion records. For each of these blood treatments, total RBC concentrates were recorded.

\section{Follow up}

All patients were followed from admission to the time of discharge from orthopaedic care and were reviewed regularly in outpatient consultation with a 2 -year follow-up.

\section{Statistics}

The populations and assessment of bleeding were compared using Student's t-test. Statistical significance was defined as a $\mathrm{P}$ value $<0.05$.

\section{Ethical Consideration}

The study was approved by the Clinical Research Ethics Committee of our hospital.

\section{Results}

\section{Blood loss}

Following the Mercurial formula, the mean Estimated Red Blood Cell (RBC) loss (ml of RBC) was 582.19 (SD 324.76) and the percentage 38.76 (SD 23.14). The mean Blood Volume Loss (BVL) calculated with Ward's formula was $1149.31 \mathrm{ml}$ (SD 551.34). Using Meunier's calculation, based on haemoglobin, we found an estimated blood loss average of $1199.35 \mathrm{ml}$ (SD 778.31).

When patients were analysed according to fracture type, we found a significant difference with regard to estimated RBC Loss andBVL according to Ward and Meunier's formulas $(\mathrm{p}<0.05)$. Blood loss was highest when treating Vancouver B3 fractures, with an estimated Red Blood Cells (RBC) loss of $850.55 \mathrm{ml}$ and Blood Volume Loss (BVL) of $1695.90 \mathrm{ml}$ according to Ward and '1781.02 ml with Meunier's formula. It was lowest when treating Vancouver A fractures, with an estimated RBC loss of $114.42 \mathrm{ml}$ and BVL of $381.06 \mathrm{ml}$ according to Ward and $423.77 \mathrm{ml}$ with Meunier's formula. Between these two extremes, bleeding was more intense in case of $\mathrm{C}$ fractures, then B2 and finally B1. In Vancouver $C$ fractures, RBC loss was $730.88 \mathrm{ml}$ and BVL was $1400.00 \mathrm{ml}$ 
(Ward) or $1366.98 \mathrm{ml}$ (Meunier). For Vancouver B2s, RBC loss was $611.47 \mathrm{ml}$ and BVL was $1101.55 \mathrm{ml}$ (Ward) or $1155.50 \mathrm{ml}$ (Meunier). Finally, for Vancouver B1s, RBC loss was $460.32 \mathrm{ml}$ and BVL was $990.00 \mathrm{ml}$ (Ward) or $1047.42 \mathrm{ml}$ (Meunier).

\section{Blood loss management methods}

The rate of postoperative transfusions was significantly high in PPHF (87.5\%). Postoperative transfusions were systematic in Vancouver B2, B3 and C fractures compared with Vancouver A $(42.9 \%)$ and B1 $(76.7 \%)$ fractures $(\mathrm{P}<0.05) .77$ patients were transfused, with each transfused patient receiving an average of 3.18 Units of blood concentrates.

The number of RBC concentrates transfused was statistically different between each different fracture pattern $(\mathrm{P}<0.05)$ in agreement with BVL. Our analysis shows high values without being statistically significant in anticoagulated patients $(\mathrm{P}>0.05)$.

\section{Discussion}

PPHFs and their surgical treatment lead to significant blood loss $[5,6]$. Marked blood loss leads to higher rates of transfusion, which may negatively affect surgical outcomes and yield greater complication rates [20]. The blood loss and transfusion rate are different between each type of fracture.

Our study is the first to evaluate blood loss and transfusion rates and conclude that these parameters are related to fracture typeand treatment. Therefore, we cannot compare our results to the previously-published data. As blood loss is different according to treatment strategy for PPHPs, it is important that the surgeon warn the anesthesiologist about the surgical procedure, to prevent this complication. Logically, Vancouver A fractures have a low bleeding volume; while conversely, Vancouver B3 fractures have the highest bleeding volume, and their coverage must be different. Precautions should therefore be considered pre-operatively to minimise the pejorative effect of postoperative anaemia according to the type of fracture.

The validity of the calculated blood loss depends upon the accuracy of the value of haemoglobin at admission time, final haemoglobin values and estimated blood volume [19,20]. The use of formulas that consider anthropometric and laboratory parameters may be valid for assessment of blood loss [21]. All these variables were calculated. However, evaluation of bleeding is underestimated due to haemodilution. Meunier et al's study [17] shows that blood loss is underestimated by more than $30 \%$ following moderate blood loss of approximately $10 \%$ of the total blood volume.

Anaemia is a pejorative factor for mortality and morbidity in PPHF populations in previous studies [22-24]. Currently, many studies are attempting to evaluate different pre-operative blood management programs to reduce postoperative anaemia [25]. A literature review on different therapeutics shows the benefit effect of Tranexamic acid (TXA) and diluted epinephrine (DEP) [26-28]. In their study, Zhang et al., [29], suggest that for patients receiving multiple boluses of intravenous TXA combined with topical TXA, erythropoietin, and iron supplements it can reduce the calculated TBL, Hb drop, transfusion rate, and postoperative morbidity and mortality. The use of intraoperative cell salvage [30] and autologous blood transfusion has proved to be safe and effective, with strong evidence shown in orthopaedic surgery. These results suggest that, with elderly patients, we should be able to improve haemoglobin levels and initiate measures to prevent blood loss [31, 32].

The influence of the surgeon's experience is difficult to analyse. In our study, $83.6 \%$ of patients were operated on by a junior surgeon, performing the same treatment for these fractures (Surgical Indication, Surgical Implant). The low values of the standard deviation among operating times in each type of fracture, suggest that in our studies, experience does not influence the bleeding. Operating time appears to be correlated with the extent of bleeding. In fact, treatment of fractures with the highest blood loss values corresponds to those with the longest operating times.

Intraoperative blood loss and transfusion rates tend to be higher in anticoagulated patients without being statistically significant $(\mathrm{P}>0.05)$. This may be due to the fact that fracture bleeding is higher in these patients.

Survival analysis is described in graph 1. This graph shows, for each fracture, that the rate of mortality is highest at 1 month and 1 year for fractures with the greatest blood loss. After one year, the slope of survival analysis looks identical. This observation suggests that bleeding after a fracture no longer affects survival beyond one year. The mortality rate after PPHF is $9 \%$ at 1 month, $28 \%$ at 1 year and $51 \%$ at the end of the study, respectively.

Graph 1. Survival Analysis.

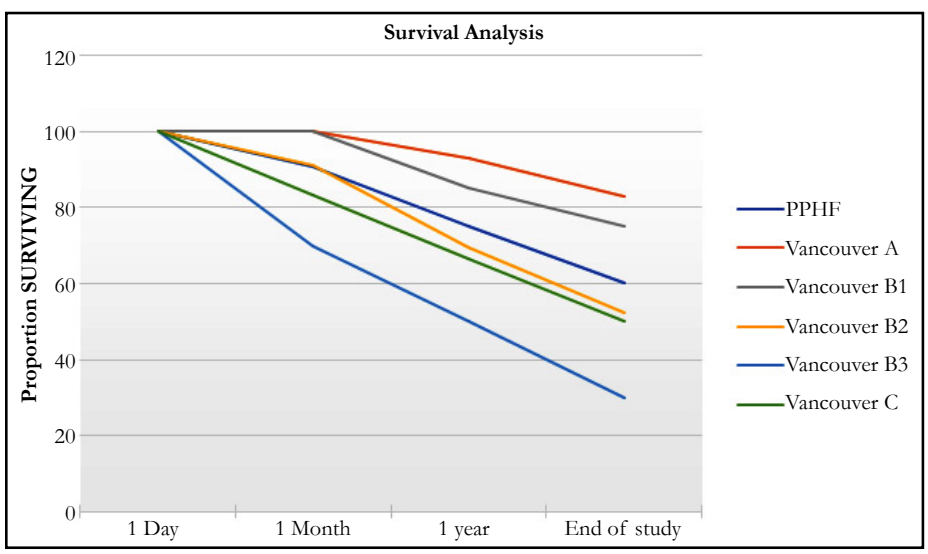


Our findings must be interpreted in light of the study's limitations, given its prospective design at a single centre institution. Moreover, we have not been able to assess the share of bleeding due to the fracture versus loss due to surgery. We tried to contact the referring physician, for all patients, but relatively few of them could provide a recent blood test. Garcia et al., [33] showed that the delta of haemoglobin was highest between $\mathrm{J}+0$ and $\mathrm{J}+1$. The monocentric design is both a limitation (small cohort) and advantage (comprehensive data collection, similar analysis of treatment of PPHF).

The study has also several strong points. The treatment of PPHF (indication, material) was always similar, in accordance withVancouver Guidelines. Moreover, different subgroups were comparable for all variables (Gender, BMI, ASA, HBpre-op, Year). All PPHFs were operated on by specialist lower limb surgeons. The decision to transfuse and the number of RBC units were dictated by HAS recommendations and by clinical findings.

\section{Conclusions}

Periprosthetic hip fractures and their treatments are associated with significant blood loss, requiring transfusion of several units of blood. The results of our study conclude, depending on the treatment for the type of fracture, blood volume loss was different in terms of estimated RBC Loss and BVL according to Ward and Meunier's formulas. Blood loss and transfusion rates are different between each type of fracture. Vancouver B3, C and B2 fractures having the highest bleeding volumes, also have the highest transfusion rates, with the maximum for Vancouver B3 fractures, with $100 \%$ of patients transfused, with an average of 3.9 Units of blood concentrates. The pejorative effect of anaemia on postoperative outcomes, reinforces the need to prevent blood loss, with promising results from the initial prevention programs.

\section{References}

[1]. Lindahl H. Epidemiology of periprosthetic femur fracture around a total hip arthroplasty. Injury. 2007;38(6):651-4. doi:10.1016/j.injury.2007.02.048

[2]. Cohen S, Flecher X, Parratte S, Ollivier M, Argenson JN. Influence of treatment modality on morbidity and mortality in periprosthetic femoral fracture. A comparative study of 71 fractures treated by internal fixation or femoral implant revision.OrthopTraumatolSurgRes. 2018 ;104(3):363367. doi: 10.1016/j.otsr.2017.12.018. Epub 2018 Feb 16.

[3]. Caruso G, Milani L, Marko T, Lorusso V, Andreotti M, Massari L. Surgical treatment of periprosthetic femoral fractures: a retrospective study with functional and radiological outcomes from 2010 to 2016.Eur J OrthopSurgTraumatol. 2018 ;28(5):931-938. doi: 10.1007/s00590-017-2082-x. Epub 2017 Nov 25 .

[4]. Kärrholm J. The Swedish Hip Arthroplasty Register (www.shpr.se).Acta Orthop. 2010 ;81(1):3-4. doi: 10.3109/17453671003635918.

[5]. Muir L. Blood transfusion requirements in femoral neck fractures.Ann R Coll Surg Engl. 1995 ;77(6):453-6.

[6]. Adunsky A, Lichtenstein A, Mizrahi E, Arad M, Heim M. Blood transfusion requirements in elderly hip fracture patients.Arch GerontolGeriatr. $2003 ; 36(1): 75-81$.

[7]. Lindahl H, Oden A, Garellick G, Malchau H. The excess mortality due to periprosthetic femur fracture. A study from the Swedish national hip arthroplasty register. Bone. 2007;40(5):1294-8. doi:10.1016/j.bone.2007.01.003

[8]. Foss NB, Kristensen MT, Kehlet H. Anaemia impedes functional mobility after hip fracture surgery. Age ageing. 2008;37(2):173-8. doi:10.1093/ ageing/afm 161

[9]. Wu WC, Smith TS, Henderson WG, Eaton CB, Poses RM, Uttley G et al. Operative blood loss, blood transfusion, and 30-day mortality in older patients after major noncardiac surgery. Ann Surg. $2010 ; 252(1): 11-7$. doi 10.1097/SLA.0b013e3181e3e43f.

[10]. Sankar A, Johnson SR, Beattie WS, Tait G, Wijeysundera DN. Reliability of the American Society of Anesthesiologists physical status scale in clinical practice.Br J Anaesth. 2014 ;113(3):424-32. doi: 10.1093/bja/aeu100. Epub 2014 Apr 11.

[11]. Baker SP, O'Neill B, Haddon W, Long WB. The injury severity score: a method for describing patients with multiple injuries and evaluating emergency care. J Trauma. 1974;14(3):187-96.

[12]. Duncan CP, Masri BA. Fractures of the femur after hip replacement. Instr Course Lect. 1995;44:293-304.

[13]. Rayan F, Dodd M, Haddad FS. European validation of the Vancouver classification of periprosthetic proximal femoral fractures. J Bone Joint Surg Br. 2008;90(12):1576-9. doi: 10.1302/0301-620X.90B12.20681.

[14]. Nadler SB, Hidalgo JH, Bloch T. Prediction of blood volume in normal human adults. Surgery. 1962;51(2):224-32.

[15]. Mercuriali F, Inghilleri G. Proposal of an algorithm to help the choice of the best transfusion strategy. Curr Med Res Opin. 1996;13(8):465-78.

[16]. Ward CF, Meathe EA, Benumof JL, Trousdale F. A computer nomogram for blood loss replacement. Anesthesiology. 1980;53(3):S126-S126.

[17]. Meunier A, Petersson A, Good L, Berlin G. Validation of a haemoglobin dilution method for estimation of blood loss. Vox sang. 2008;95(2):120-4. doi:10.1111/j.1423-0410.2008.01071.x

[18]. Wertheimer A, Olaussen A, Perera S, Liew S, Mitra B. Fractures of the femur and blood transfusions. Injury. 2018;49(4):846-51. doi:10.1016/j. injury.2018.03.007.

[19]. Gross JB. Estimating allowable blood loss: corrected for dilution. Anesthesiology. 1983;58(3):277-80. doi:10.1097/00000542-198303000-00016

[20]. Foss NB, Kehlet H. Hidden blood loss after surgery for hip fracture. J Bone Joint Surg Br. 2006;88(8):1053-9. doi:10.1302/0301-620X.88B8.17534

[21]. Lopez-Picado A, Albinarrate A, Barrachina B. Determination of Perioperative Blood Loss: Accuracy or Approximation. AnesthAnalg. 2017;125(1):280286. doi: 10.1213/ANE.0000000000001992.

[22]. Carson JL, Terrin ML, Jay M. Anemia and postoperative rehabilitation. Can JAnaesth. 2003;50(6):60-4.

[23]. Carson JL, Noveck H, Berlin JA, Gould SA. Mortality and morbidity in patients with very low postoperative $\mathrm{Hb}$ levels who decline blood transfusion. Transfusion. 2002;42(7):812-818.

[24]. Carson JL, Duff A, Poses RM, Berlin JA, Spence RK, Trout R, et al. Effect of anaemia and cardiovascular disease on surgical mortality and morbidity. Lancet. 1996:348(9034):1055-60.

[25]. Muñoz M, Gómez-Ramírez S, Liumbruno GM. Peri-operative anaemia management in major orthopaedic surgery: the need to find a pathway. Blood transfus. 2017;15(4):289-91. doi: 10.2450/2017.0296-16

[26]. Schiavone A, Bisaccia M, Inkov I, Rinonapoli G, Manni M, Rollo G et al.Tranexamic Acid in Pertrochanteric Femoral Fracture: Is it a Safe Drug or Not? Folia Med. 2018;60(1):67-78. doi:10.1515/folmed-2017-0070.

[27]. Good L, Peterson E, Lisander B. Tranexamic acid decreases external blood loss but not hidden blood loss in total knee replacement. Br J Anaesth. 2003;90(5):596-9. doi:10.1093/bja/aeg111

[28]. Wu Y, Zeng Y, Bao X, Xiong H, Fan X, Shen B.Application of tranexamic acid and diluted epinephrine in primary total hip arthroplasty. Blood Coagul Fibrinolysis. 2018;29(5):451-457. doi:10.1097/MBC.0000000000000743.

[29]. Zhang S, Huang Q, Xu B, Ma J, Cao G, Pei F. Effectiveness and safety of an optimized blood management program in total hip and knee arthroplasty: a large, single-center, retrospective study. Medicine. 2018;97(1):e9429. doi:10.1097/MD.0000000000009429.

[30]. Ashworth A, Klein AA. Cell salvage as part of a blood conservation strategy in anaesthesia. Br J Anaesth. 2010;105(4):401-16. doi:10.1093/bja/aeq244

[31]. Halm EA, Wang JJ, Boockvar K, Penrod J, Silberzweig SB, Magaziner J, et al. The effect of perioperative anemia on clinical and functional outcomes in patients with hip fracture. J Orthop Trauma. 2004;18(6):369-74. doi:10.1097/00005131-200407000-00007

[32]. Lawrence VA, Silverstein JH, Cornell JE, Pederson T, Noveck H, Carson $\mathrm{JL}$. Higher $\mathrm{Hb}$ level is associated with better early functional recovery after hip fracture repair. Transfusion. 2003;43(12):1717-22. doi:10.1046/j.00411132.2003.00581.x

[33]. García-Erce JA, Cuenca J, Haman-Alcober S, Martínez AA, Herrera A, Muńoz M. Efficacy of preoperative recombinant human erythropoietin administration for reducing transfusion requirements in patients undergoing surgery for hip fracture repair. An observational cohort study. Vox Sang. 2009;97(3):260-7. doi: 10.1111/j.1423-0410.2009.01200.x. 